Duchenne de Boulogne was among the first to investigate neuromuscular diseases. He stimulated muscle and nerve with moistened surface electrodes, thereby avoiding tissue necrosis. Technique and self-designed equipment are discussed in his first major work de l'électrisation localisée. During his 30 years of practice, he examined several hundred patients with poliomyelitis. With electrodiagnostic evaluation, he focused on "electrocontractility," the intensity of muscle contraction elicited by electrical stimulation. Based on his electrophysiologic findings, Duchenne suggested that the responsible lesion resided within the spinal cord. He used electrical stimulation for treatment and recognized prognostic features.

Key words: poliomyelitis • Duchenne de Boulogne • history of neurology • history of electrodiagnosis

MUSCLE \& NERVE $\quad 13: 56-62 \quad 1990$

\title{
DUCHENNE de BOULOGNE: ELECTRODIAGNOSIS OF POLIOMYELITIS
}

\author{
HANNA REINCKE, MD, and KEVIN R. NELSON, MD
}

As one of the founders of electrodiagnosis, Duchenne de Boulogne (1806-1875) was the first to systematically study neuromuscular diseases. Technique and equipment of electrical stimulation (Fig. 1) are described in Duchenne's first major work, de L'électrisation Localisée. ${ }^{3}$ An ardent investigator, Duchenne contributed greatly to the discovery of many neurologic illnesses and provided insight into the actions of various muscles. ${ }^{5}$

After the death of his beloved wife and a brief discordant second marriage, Duchenne abandoned his well-established practice in the small seaport of Boulogne and moved to Paris. His reception in the parisian medical community was cold (Refs. 1, 7, 12, and 13:pp 313-322). Duchenne was ridiculed for his provincial accent and coarse manners. Although his interest in electrodiagnosis met with scorn, Duchenne continued to pursue his investigation of neuromuscular disease.

From the Department of Neurology, University of Michigan Medical Center, Ann Arbor, Michigan (Dr. Reincke) and the Department of Neurology, University of Kentucky, Lexington, Kentucky (Dr. Nelson).

Acknowledgment: The authors thank Ernst Jokl, MO, for providing original material and encouragement.

Presented in part at the annual meeting of the American Association of Electromyography and Electrodiagnosis in San Antonio, TX, October 1987

Address reprint requests to Dr. Nelson at the Department of Neurology, University of Kentucky Medical Center, 800 Rose Street, Lexington, KY 40536-0084.

Accepted for publication October 21, 1988

CCC 0148-639X/90/01056-07 \$04.00

(C) 1990 John Wiley \& Sons, Inc
His talents and original ideas were later appreciated by the eminent hospital chiefs Troussau and Charcot, who kindly welcomed Duchenne into their hospitals. In Paris he went by the name of Duchenne de Boulogne to distinguish himself from Duchesne of Paris, a fashionable physician of the parisian aristocracy. ${ }^{1}$

Duchenne neither sought nor was offered a hospital appointment. The freedom from daily hospital responsibilities enabled him to devote full attention to his most interesting cases, sometimes followed from hospital to hospital during the years of their illness. Based on the detailed notes of many patients' cases, Duchenne derived his original descriptions of diseases such as poliomyelitis, bulbar palsy, and "pseudohypertrophic muscular paralysis" which now carries his name (Fig. 2).

\section{DUCHENNE'S EQUIPMENT AND TECHNIQUE}

One of Duchenne's major technical achievements was the development of a safe and comfortable mode of electrical stimulation utilizing surface electrodes. He thereby avoided abscess formation and tissue necrosis, which were frequent complications encountered after "electropuncture." A technique of needle stimulation, electropuncture was developed by Duchenne's former teacher $\mathrm{Ma}$ gendie and another of his students, Sarlandière.

Duchenne considered himself the inventor of muscle and nerve "localized faradization," giving credit to the inventor of induced electricity, Faraday. "I was able to produce instruments made by 


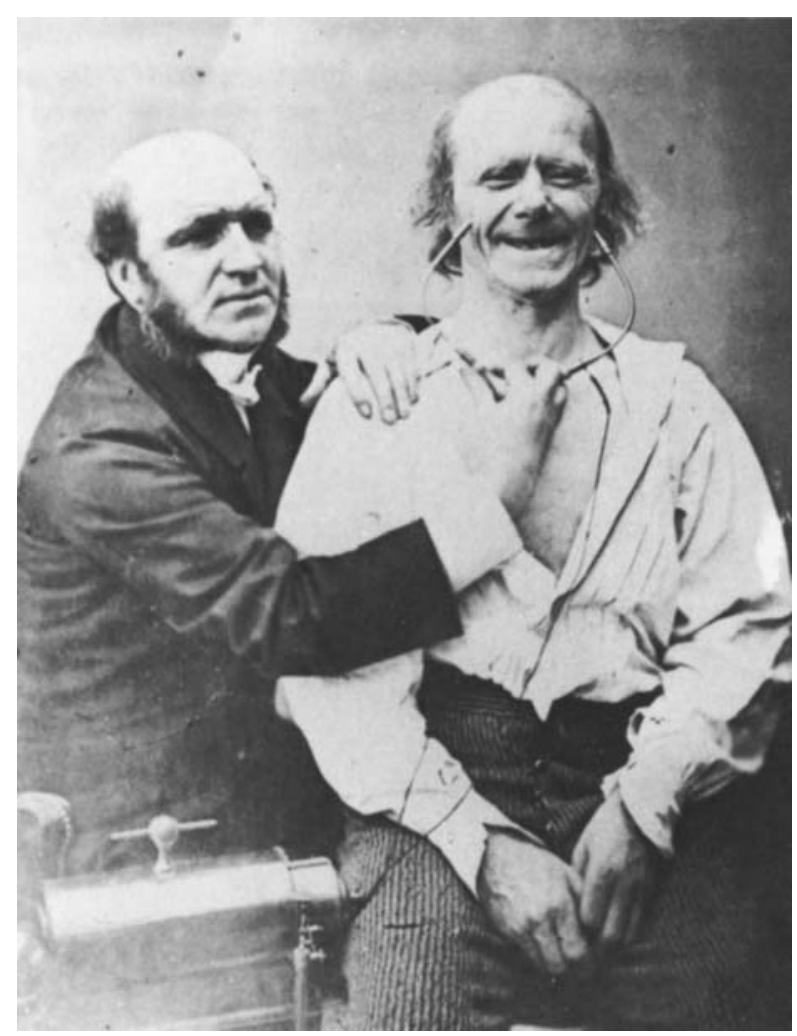

FIGURE 1. Duchenne de Boulogne eliciting a contraction of facial muscle. This original photograph, although possibly posed, demonsrates Duchenne's equipment and technique of stimulation. He considered the facial muscles among the most sensitive to stimulation.

my own hands, although I had previously never used a file or hammer." ${ }^{4}$ Duchenne first presented his electrical equipment to the Académie des Sciences in 1848. A carbon-zinc voltaic pile served as battery and was connected to a primary coil (Fig. 3). A superimposed secondary coil provided the induced current most often used for stimulation. The exact waveform of stimulating current employed by Duchenne is not known with certainty but most likely rose and decayed without a change in polarity. A vibrating switch (buzzer) interrupted the circuit to the primary coil at an adjustable frequency, the "intermittence." Slower intermittences were produced with a pedal switch. His apparatus produced sustained or repeated contractions depending on the frequency of stimulation. Duchenne was aware of many factors that influenced stimulus strength. For most studies, a copper cylinder was moved over the induction coils and varied the intensity of current delivered to the patient. The intermittence rate and stimulus strength used depended on excitability of the muscle studied and medical condition of the patient.

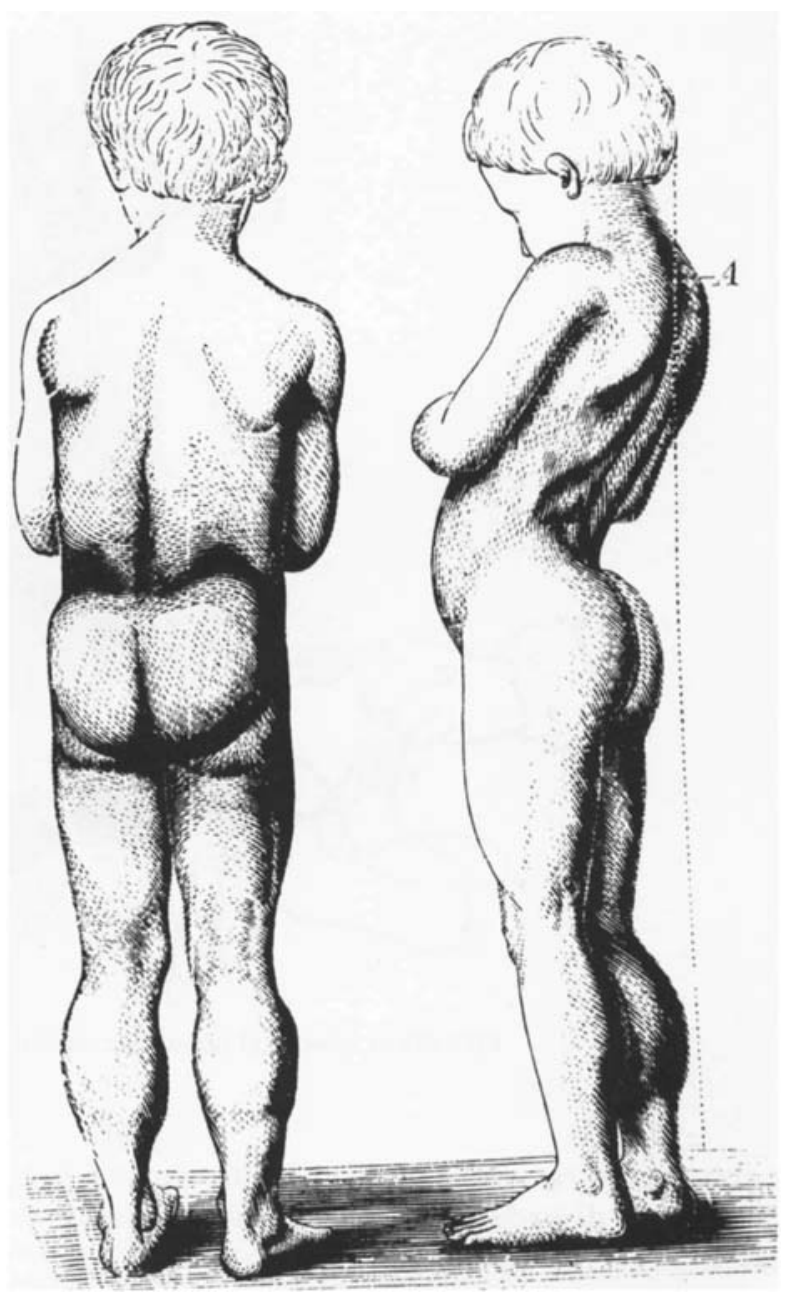

FIGURE 2. Duchenne illustrated many cases with his own drawings. This one depicts "pseudohypertrophic muscular paralysis," the disease which now bears his name.

Duchenne stimulated muscle and nerve by applying two surface electrodes ("rheophores") to moistened skin. The two electrodes were held by one hand in a bipolar fashion while the examiner operated the apparatus with his free hand. Depending on electrode position, contraction of a muscle group, single muscle, or fascicle was elicited. This procedure of "faradization" enabled Duchenne to study the physiologic action of isolated muscles. Duchenne distinguished between "indirect" muscular stimulation via nerve, which resulted in contraction of several muscles, and "direct" stimulation of a single muscle. However, the precise sites he used for electrode placement were controversial even in his own time (Ref. 7, pp 6470). In his book, Physiologie des Movements, ${ }^{5}$ he systematically elucidated observations on the action of individual muscles and muscle groups in 


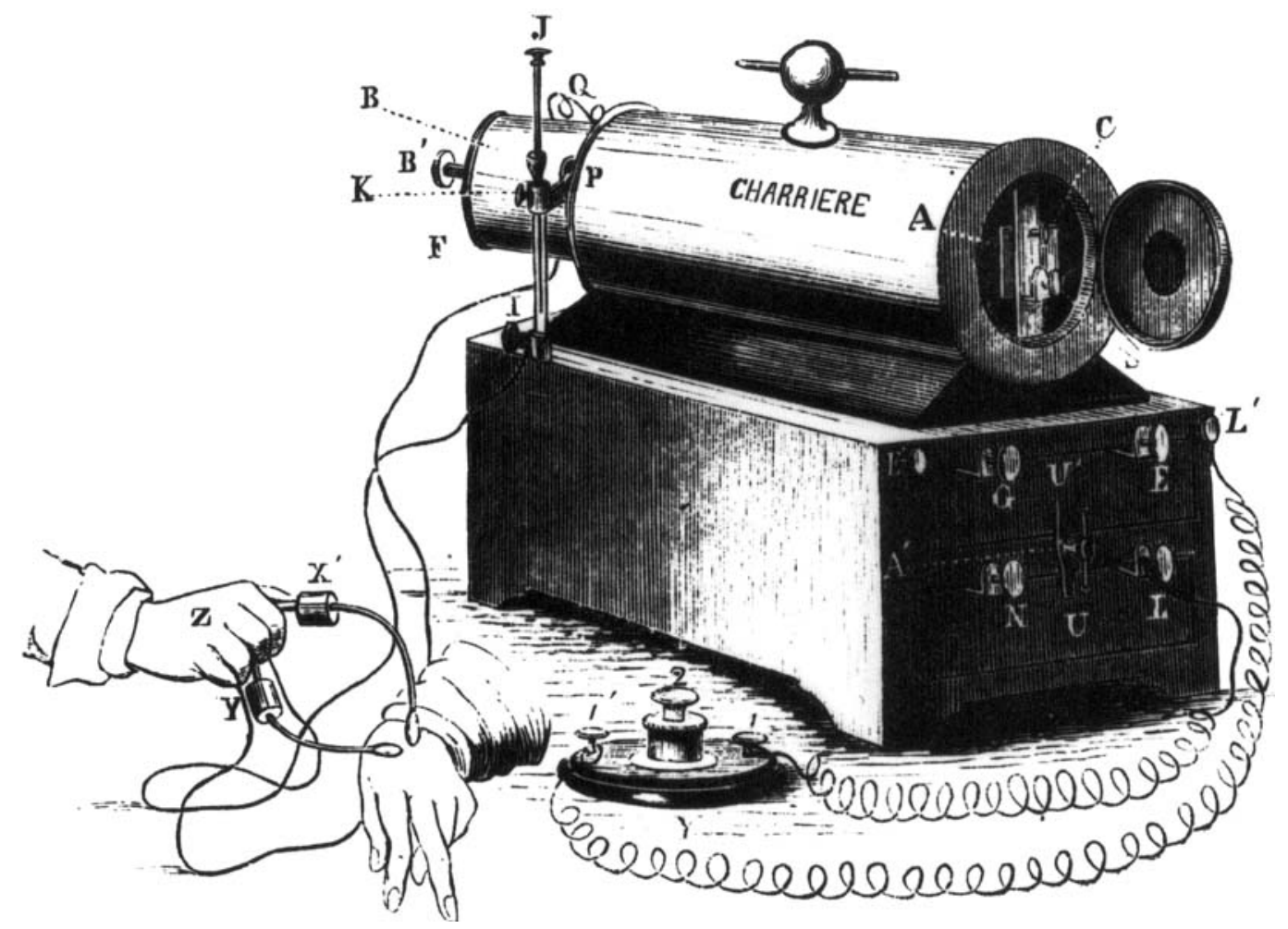

FIGURE 3. Electrical apparatus: application of two electrodes to interosseous muscle.

healthy subjects, and in subjects with various neuromuscular disorders as well as isolated nerve injuries.

Duchenne constructed specific electrodes to stimulate different body parts (Fig. 4). For large muscles of the trunk, large cyclindrical electrodes were used. Application of the electrical charge was facilitated by moistened sponge or leather within the cylinder. Delicate muscles of face and hand

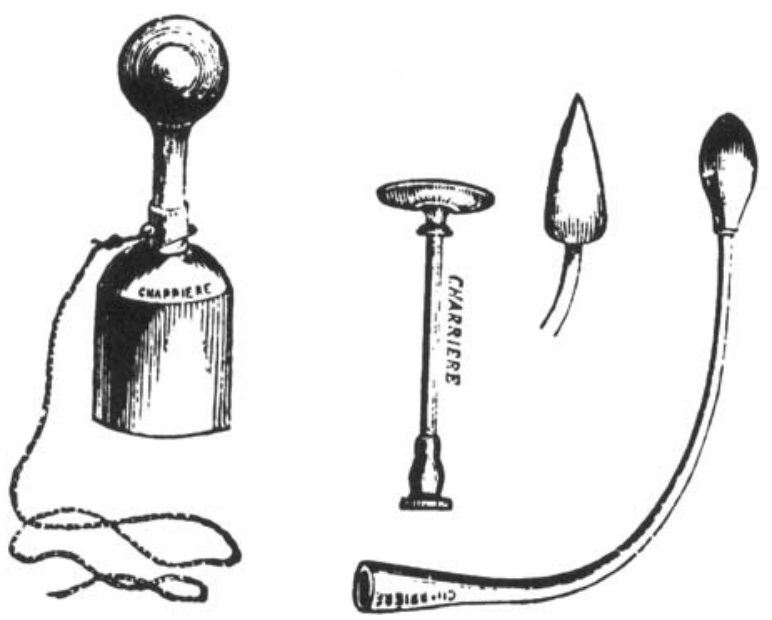

FIGURE 4. Electrodes for muscular and cutaneous stimulation. were stimulated with small, conical electrodes. He also stimulated skin and internal organs such as bladder and rectum for various therapeutic purposes.

Duchenne was not popular with hospital staff. $\mathrm{He}$ therefore devised a portable apparatus the size of a book which could easily be handled at the bedside of the patient, without disturbing hospital routine (Fig. 5).

\section{ELECTRODIAGNOSIS OF POLIOMYELITIS}

During his 30 years of practice in Paris, Duchenne had opportunity to examine several hundred patients with poliomyelitis for which he coined the term "infantile atrophic paralysis." In 1854 he presented his observations to the Académie de Médicine in Paris ${ }^{6}$ and devoted an entire chapter in the first edition of De L'électrisation Localisée to this subject. This disease was first recognized as a distinct entity in England at the end of the eighteenth century. ${ }^{14}$ In Duchenne's time, poliomyelitis was a disease of infancy and early childhood. The endemic prevalence of this illness was probably due to the poor sanitary practices of the nineteeth century. ${ }^{10}$

Duchenne gave a clear and comprehensive account of the clinical characteristics of poliomyeli- 


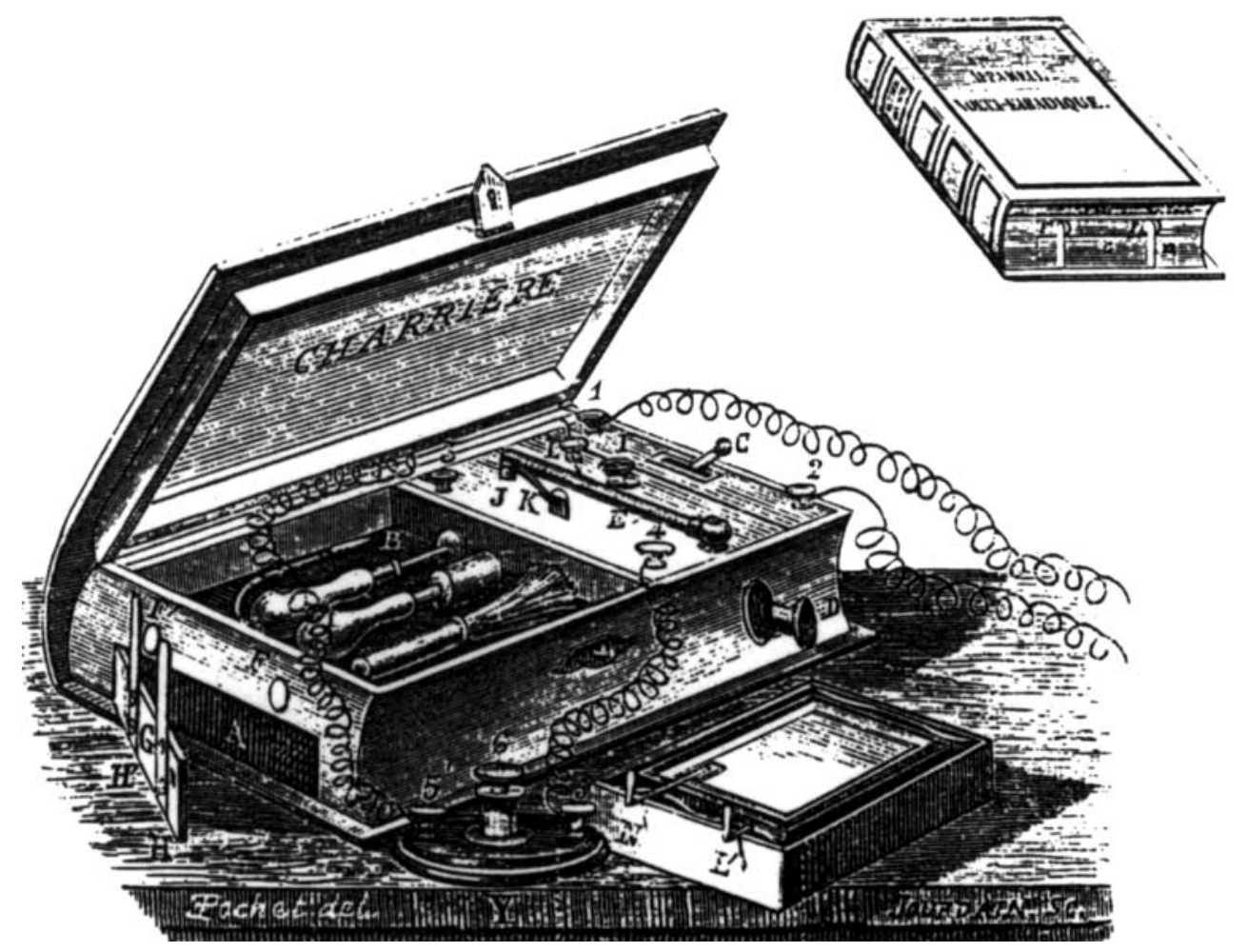

FIGURE 5. Duchenne used a book-sized portable electrical apparatus for most of his studies.

tis. The diagnosis was reliably made on the basis of typical features, and it is likely that his cases did indeed fit this modern disease category. At the time of evaluation, the great majority of his patients were chronically paralyzed. He saw some patients shortly after the onset of the acute illness, and reexamined these frequently.

Duchenne concentrated on the most interesting cases and documented his findings with illustrations and extensive notations. After a comprehensive history, he noted the size of the extremity, individual muscle bulk, temperature, and any abnormality of posture. During the electrodiagnostic evaluation he focused on the intensity of muscle contraction elicited by electrical stimulation, or "electrocontractility." He examined muscles of the afflicted limb with a stimulus of increasing intensity until maximum contraction was achieved, as judged by clinical observation.

In the first and second editions of $D e$ L'électrisation Localisée, Duchenne presented a patient illustrating the typical course of poliomyelitis and his technique of examination. He described a $41 / 2$-year-old girl who suddenly lost use of her left $\mathrm{arm}$. The same evening she developed paralysis of the right leg, neck, and trunk. Strength gradually returned in the muscles of neck and trunk, followed by recovery of muscles in the forearm. The leg later improved, but the peroneus muscles remained paralyzed. Fifteen months later Duchenne made the following observations:

The left upper extremity was much less well developed than the right. There was marked wasting of the deltoid. The head of the humerus projected through the wasted musculature and appeared to be pulled away from the glenoid fossa (they both stayed in contact only through the capsule of the joint). There was marked wasting of the infraspinous musculature, the flexor muscles of the forearm and the triceps. A right equinovarus deformity was found. Mobility of the peroneus muscles and the extensor longus digitorum was lost. With electrical exploration, no contractions could be elicited in the left deltoid and infraspinous muscles. Some contractions were observed in the biceps and triceps in spite of considerable atrophy. In the right leg, no contraction was elicited in the peroneus muscles or extensor digitorum longus. There was growth retardation of the bony structures in the area of the muscular atrophy: the left scapula was smaller than the right; (comparing the distance between the inferior angle and the acromion, a $1 \mathrm{~cm}$. difference was found between both scapulae). The humerus, tibia and the bony structures of the foot were notably smaller. The temperature in the left arm and right leg was diminished. After eight treatments with localized faradisation, flexion and ex- 
tension in the forearm improved. With forty more treatments, flexion in the elbow returned and enabled the patient to use her left hand, in which the muscles were left intact. ${ }^{3}$ (pp. 843-844 first edition)

The degree of impaired "electrocontractility" in the affected muscles served as a clue to the potential for recovery. Such observations were interpreted by Duchenne in the context of the acute or chronic phase of illness. In the acute phase, impairment of contractility suggested the muscle was in great danger, while the same finding in the chronic paralytic phase indicated muscle fiber loss and substitution by fatty tissues. Duchenne believed the patient's outcome depended on both the severity of paralysis and the functional importance of the affected muscles. He emphasized the importance of hip muscles for locomotion, the deltoid and flexors of the elbow for function of the upper extremity, and the thenar muscles for hand function.

Faradization not only aided Duchenne in his assessment of the prognosis for recovery, but was also used as therapy for weakened muscles. Electrical treatments usually began after the fever had subsided. Duchenne thought the inititation of therapy early after the acute phase would lessen the duration of the paralysis and diminish, if not prevent muscular wasting and substitution by fatty tissue. He observed rapid improvement of power in the mildly compromised muscles, while severely wasted muscles were resistant to all forms of theapy. A strength gauge he invented was sometimes used to follow recovery of voluntary strength (Fig. 6). Duchenne also designed splints and orthotic devices for patients with severe paralysis to help them stand and walk or to improve the joint deformities resulting from alteration of muscle balance (Fig. 7).

Although the clinical features of poliomyelitis were well established in the early nineteenth century by Monteggia, ${ }^{9}$ Heine, ${ }^{8}$ and others, there was disagreement over the site of pathology. Some of Duchenne's French contemporaries maintained there was no organic lesion and the paralysis was beyond contemporary explanation or "essential" in nature. ${ }^{2,11}$ Duchenne opposed this view and criticized that the spinal cord of poliomyelitis victims had not been microscopically examined ( $D e$ L'électrization Localisée, ed 3, p $402^{3}$ ). On the basis of his experience with many detailed electrodiag. nostic case studies, Duchenne proposed that paralysis resulted from an alteration of the spinal cord.
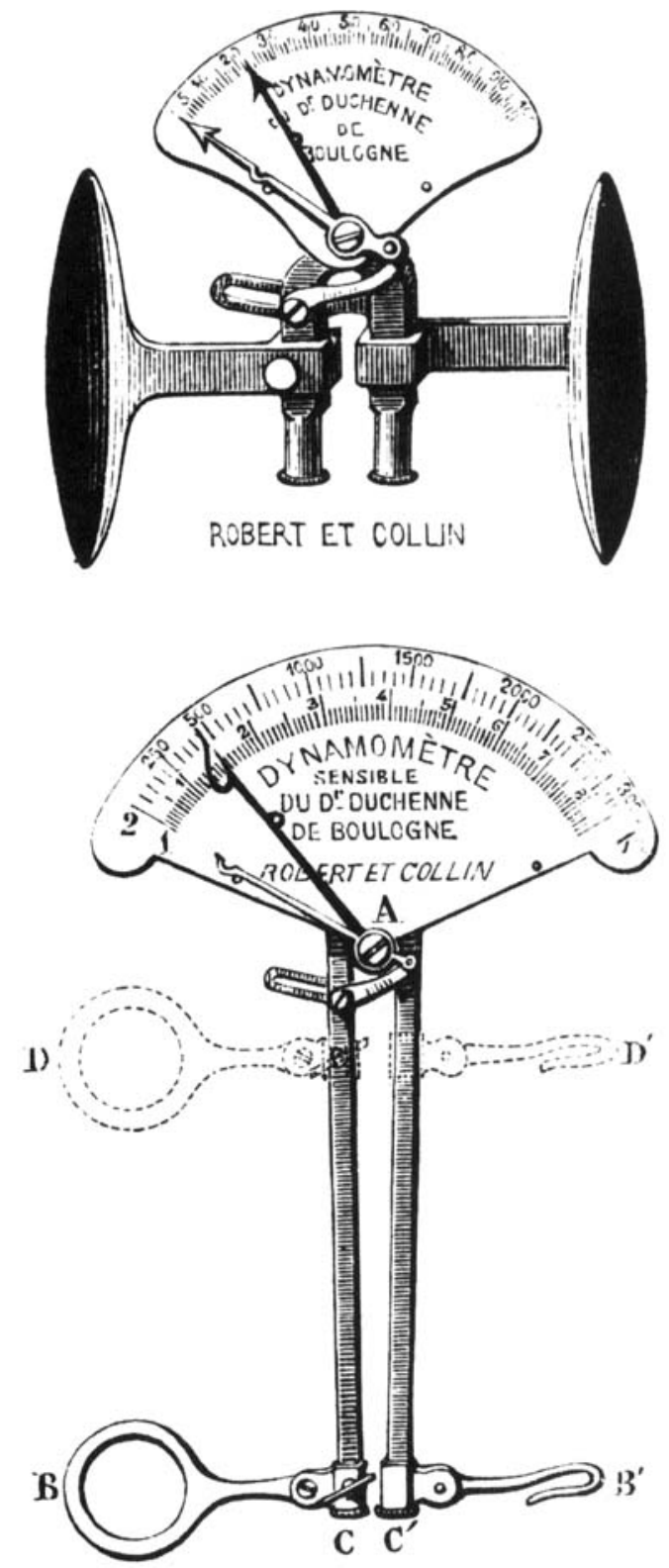

FIGURE 6. Strength gauges invented by Duchenne.

Clinial intuition may have played a major role in this hypothesis. He was impressed by similarities between poliomyelitis and spinal cord injuries; in both he observed a sudden onset of symptoms followed by improvement in some muscles and persisting weakness in others. In his evaluation Duchenne emphasized abnormalities of muscle bulk and strength. Differences between spastic and flaccid paralysis were not recognized. Later, physical examination became more refined with discovery of the Babinski response and deep tendon reflexes at the end of the nineteenth century (Ref. 13:pp 327-328).

Duchenne, whose primary interest was elec- 


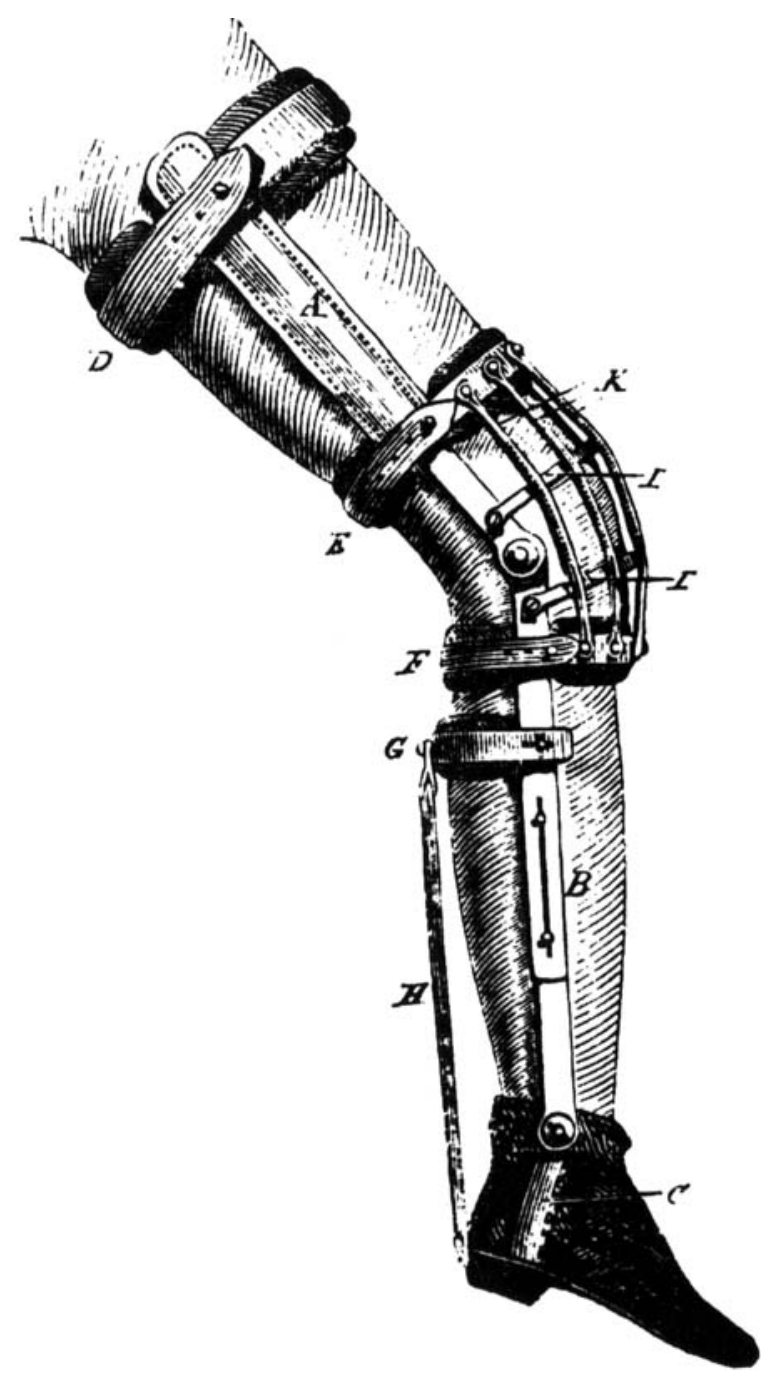

FIGURE 7. Orthotic splint designed by Duchenne for a patient with poliomyelitis.

trodiagnosis and clinical neurology, initially had little access to postmortem examinations. This made it difficult to correlate his clinical observations with pathologic findings. Due to these constraints, he developed a needle for muscle biopsy (Fig. 8). Under the influence of Charcot at the Salpetrire in the late $1860 \mathrm{~s}$, Duchenne's hypothesis that poliomyelitis is due to an alteration of spinal cord proved correct, although Duchenne himself did not make the original observations. In the third edition of De L'électrisation Localisée, Duchenne published several camera lucida drawings of spinal cord sections.

\section{CONCLUSION}

In his later years, Duchenne became highly regarded and was consulted by many well-known

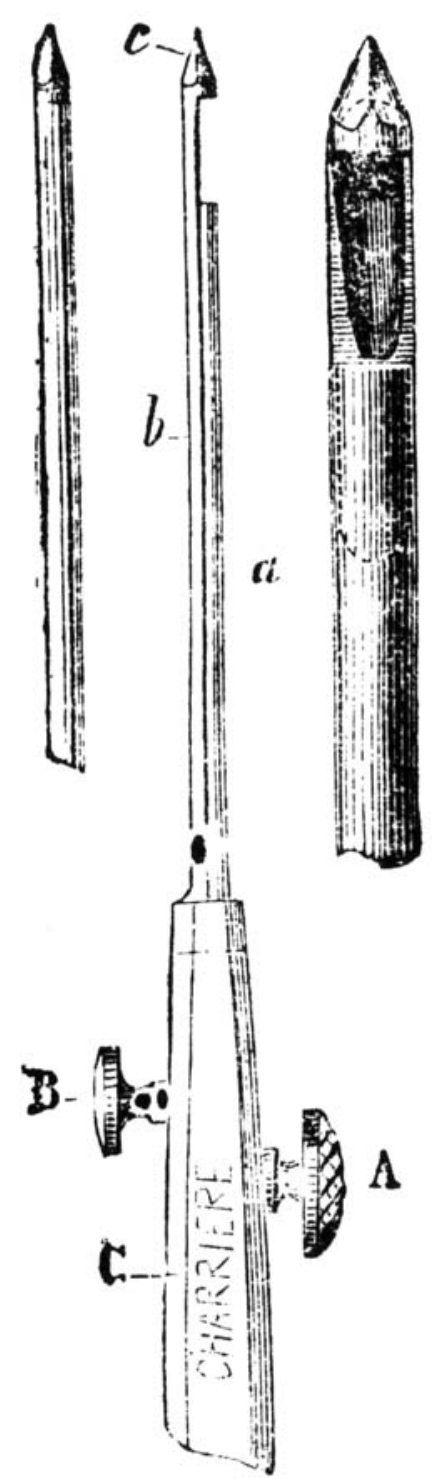

FIGURE 8. Duchenne's muscle biopsy needle.

and respected physicians. Numerous patients sought his advice, and his practice prospered. In addition to his clinical work, Duchenne experimented with electricity and the medical application of recently invented photography (Fig. 1). Some of his photographs were published in $D e$ L'électrisation Localisée.

In 1875 Duchenne died of a cerebral hemorrhage. Although honored by many foreign universities and societies, Duchenne never belonged to a french university or academy. His contributions to the study of electrodiagnosis and and neuromuscular disorders are unparalleled, and he can truly be called one of the founding fathers of modern neurology. 


\section{REFERENCES}

1. Collins J: Duchenne of Boulogne. Med Rec. 1908;73:5054 .

2. de Nancy R: Un mot sur la paralysie essentielle chez les enfants. Bull Gén Thérap. 1849;36:120.

3. Duchenne GBA: De L'électrisation Localisée et de Son Application à la Physiologie, à la Pathologie et à Thérapeutique. Paris, Ballière, 1855 (lst ed), 1861 (2nd ed), 1872 (3rd ed). (English translation: Duchenne (de Boulogne) GBA; Poore GV, trans-ed: Selections from the Clinical Works of Duchenne (de Boulogne). London, The New Sydenham Society, 1883.)

4. Duchenne GBA: Localized Electrization, and Its Applications to Pathology and Therapeutics. Translated from the 3 rd ed by Tibbits, H. Philadelphia, Lindsay and Blakiston, 1871, p 243.

5. Duchenne GBA: Physiologie des Movements. Paris, Ballière, 1867.

6. Duchenne GBA: De la paralysie atrophique graisseuse de l'enfance, et de son traitement par l'électrisation localisée.
Mémoire addressé à l'Académie de Médecine le 5 septembre 1854. Gaz Hebd 1855

7. Guilly P: Duchenne de Boulogne. Paris, Ballière, 1936

8. Heine I: Beobachtungen über Lähmungszustände der unteren Extremitäten und deren Behandlung. Stuttgart, Köhler, 1840.

9. Monteggia GB: Instituzione Chirurgicale, ed 2. Milano, Maspero, 1813, vol 1

10. Paul JR: A History of Poliomyelitis. New Haven, Yale University Press, 1971 , p 22.

11. Rilliet F: De la paralysie essentielle chez les enfants. Gaz Méd Paris. $1851 ; 6: 681-704$.

12. Robinson V: Duchenne of Boulogne (1806-1875), in Robinson V ed: Syllabus of Medical History. New York, Froben Press, 1933, pp 51-66.

13. Spillane JD: The Doctrine of the Nerves, Oxford, Oxford University Press, 1981.

14. Underwood M: A Treatise on Diseases of Children with General Directions for the Management of Infants from the Birth, ed 2. London, Mathews, 1789 